\title{
Design and Analysis of Injection Mould for 10- Position Drawer Housing Connector
}

\author{
Akshay B Bhat ${ }^{1}$ \\ Mtech, Student \\ Department of Tool engineering \\ Government tool room and training centre \\ Mysore, India
}

\author{
Dr. N Ramesha ${ }^{2}$ \\ Principal of PG studies \\ Department of Tool engineering \\ Government tool room and training centre \\ Mysore, india
}

\begin{abstract}
Plastic products are on high demand in the modern world, because of its several useful properties. One of the most popular ways of manufacturing plastic products is by injection moulding process. To produce the shape required a mould tool is required. The focus of this paper is moulding of electrical housing connectors. The component material is PolyButylene Terephthalate 30\% Glass Filled. General molding is sufficient to produce this component. First component study and design is done for better understanding. Prior to manufacturing of tool a conceptual design is done since manufacturing requires designs and drawings for reference. Keeping in mind the physical and thermal properties of material, mould flow analysis gives a better understanding and required exact parameters for the tool design such as good gate location, runner cross-section, etc. The tool design starts from extraction of core and cavity and then the other elements are designed. The software used for design is NX.11 and one used for analysis is NX Easy Fill Advanced. The tool design should be designed economical, accurate and according to the machine specifications. Therefore tool should produce accurate products for required production and tool life.
\end{abstract}

Keywords - Housing Connector, Masterbatch, Contact cavities, Pin protector, Mold flow, submarine gate.

\section{I.INTRODUCTION}

Plastics are one of the most widely used materials for countless applications. They are versatile, lightweight and durable. There are several processes of converting plastic raw materials into the final product. The most famous and widely used process is Injection Moulding. The raw plastic is melted in the injection moulding machine and then injected into the mould through a gate. Then it cools and solidifies finally ejecting the finished product. The equipment used to mold and shape the component is called the injection mold. The process cycle of injection molding mainly consists of four stages- Melting, Injection, Cooling

\section{and Ejection.}

In the melting stage, mold is closed and plastic granules in the hopper are gravity fed into the heated barrel and rotating screw. The granules are because of high pressure, friction and temperature. Injection is the stage when molten plastic is injected into the mold cavity by forcing it by means of rotating screw. Pressure is maintained until good packing of material is achieved and cooled. The next stage is cooling of the part often achieved by cooling circuits given in the mold. Water is circulated in these circuits to solidify the part and maintain mold temperature. As the screw retracts backward, the final ejection stage takes place where mold is opened and ejector mechanism pushed out component from mold. This completes one full cycle as the mold closes for next cycle.

To obtain an idea of the methodology for the process, similar papers are referred. In [1] the mold design and analysis for a four cavity cable ceiling holder base is done. A modified circular component is produced from a previously existing square shaped model. Analysis such as filling time and cooling time is also shown. In [2] and [3] conceptual mold designs for their respective components is done and methodology is explained. In [4] a design and analysis is done for a FRP component and results such as pressure distribution, fill time, weld lines, etc are shown. Paper [5] included a detailed study and methodology to produce L\&T power box side panel. These included calculations, analysis and complete mold design and explanation. These papers gave an idea on the methodology and process chart required to carry out this research.

\section{II.OBJECTIVES}

- Detailed study and design of component.

- Design and analysis of one full shot.

- Calculation and conceptual design of injection mould.

- To produce the component with no major defects.

\section{III.ABOUT THE COMPONENT}

Since the increase in number of electrical and electronic products, the electronic industry is exponentially raising 
therefore more demand for manufactured parts. Electrical circuits consist of many components and parts including wires and cables. Connectors are devices which act as an interface to connect two electrical circuits. The male connectors are called as plug and female are called sockets. Connectors have housing and terminals in which housing for stability is of plastic material and terminals made of conductive materials. This paper focuses on injection mould design and validation for a housing connector socket. The component is made of PolyButylene Terephthalate $30 \%$ Glass Filled. Black masterbatch is added to produce the component of respective colour. Allowable regrind is $25 \%$ according to the customer.

Material Properties of PolyButylene Terephthalate 30\% GF:

\begin{tabular}{|c|c|}
\hline Properties & Value \\
\hline Density & $1.50 \mathrm{~g} / \mathrm{cc}$ \\
\hline Tensile strength at break & $131 \mathrm{MPa}$ \\
\hline Elongation at break & $3.0 \%$ \\
\hline Melting point & $223^{\circ} \mathrm{C}$ \\
\hline Shrinkage & $0.3-1.6 \%$ \\
\hline Coefficient of linear expansion & $6-10 \times 10^{-5} /{ }^{\circ} \mathrm{C}$ \\
\hline
\end{tabular}

\section{METHODOLOGY}

\section{Model Study and Design of Component:}

The model is studied from the 2D drawing. The part has ten contact cavities, a pin protector and two guide post cavities on diagonal ends. It has four ribs on the socket side for stability and strength. 3D model is done by using NX11.0 software. It is very essential to give drafts in the vertical features for easy ejection from mold and avoiding catching unless no draft is mentioned in the drawing. Criticality involved in the component includes ten contact cavities and pin protector.

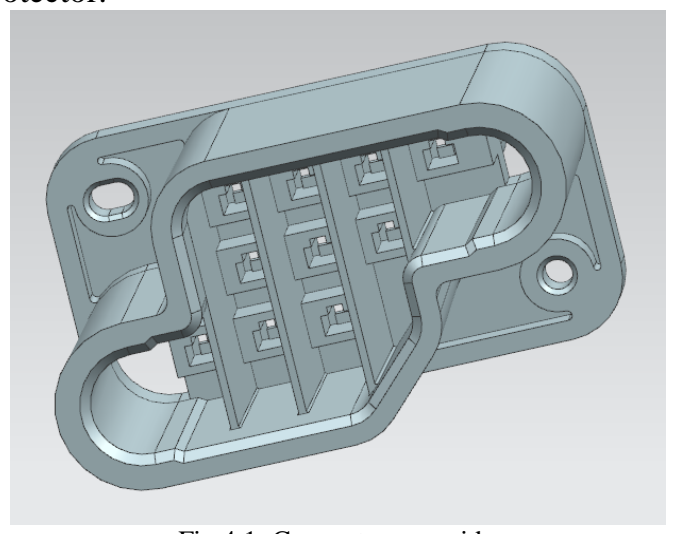

Fig 4.1: Connector core side

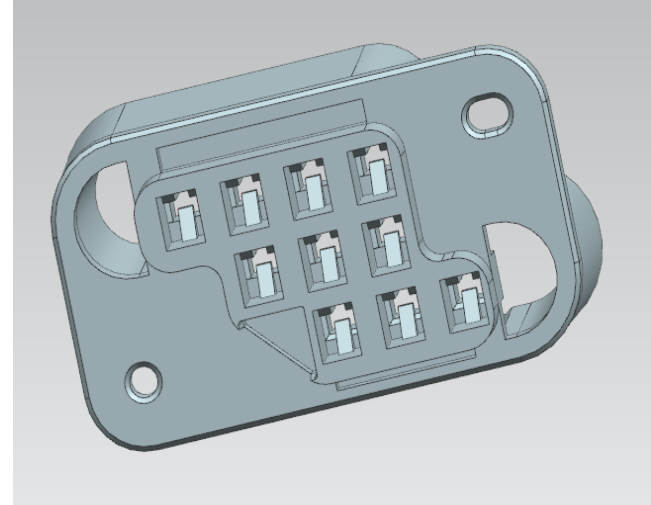

Fig 4.2: Connector cavity side

\section{Mould Flow Analysis:}

Mould flow analysis is a simulation for the flow of plastic material which helps to evaluate the part, parameters and mould design to produce good quality parts. The analysis can give results such as fill time, cooling time, flow pressure, etc and can indicate defects such as location of weld lines, air traps, short shot, burn marks, etc. Reducing weld lines in this component is one of the important aspects since these defects in critical areas may cause failures. Weld lines are V-notches that arises due to poorly bonded regions near the surface and with shrinkage as a result of extremely high molecular orientations induced at the end of filling [6].

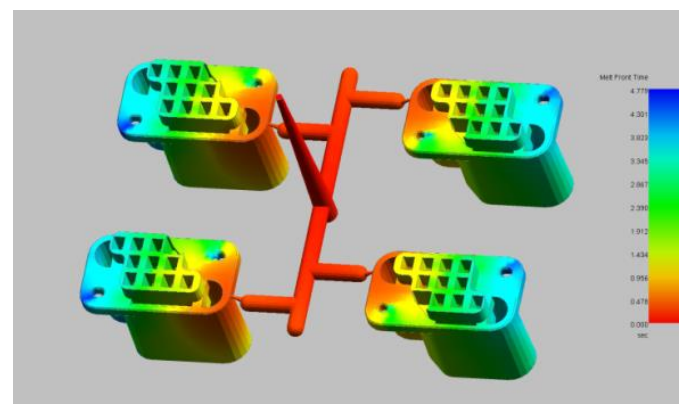

Fig 4.3: Melt Front Time

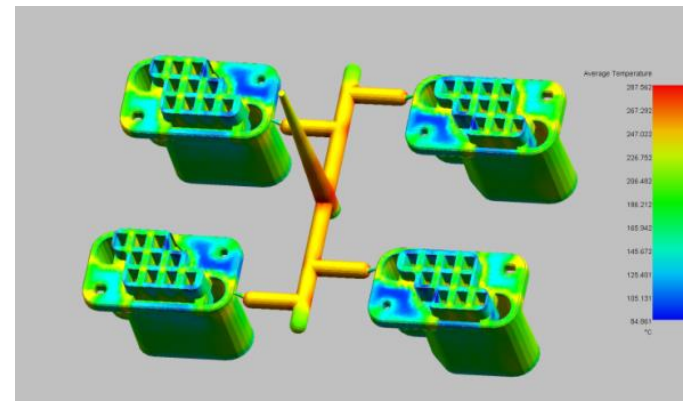

Fig 4.4: Average Temperature 


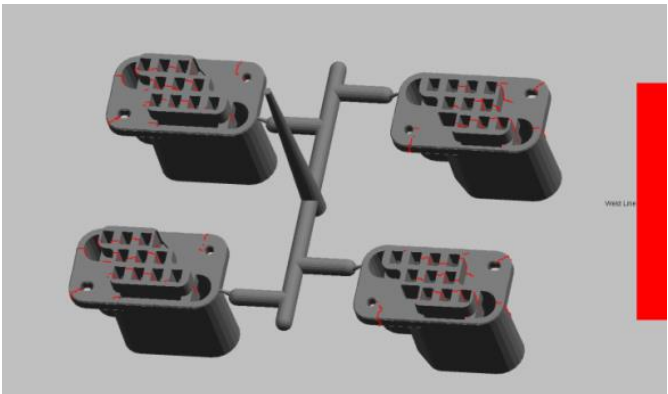

Fig 4.5: Weld Line

Using the flow analysis software the best gate positions can also be decided. The arrow shows approximate location of gate. Here the software is used to decide the gate position so that the position results in complete filling of component and to avoid defects as much as possible. Several trials are taken in which the gate position is placed in different locations. The location which gives the best results are implemented.

\section{Trial 1:}

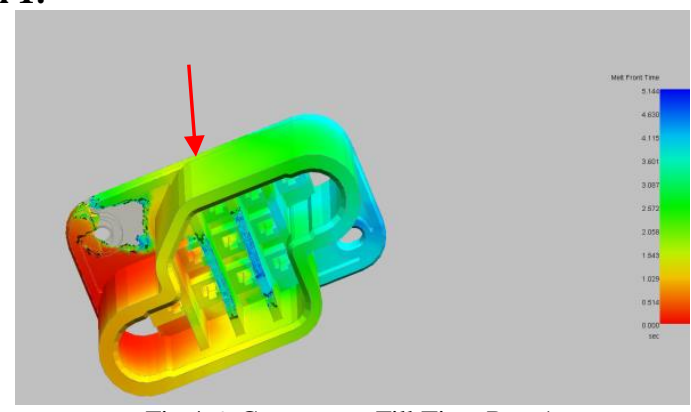

Fig 4.6: Component Fill Time Run 1

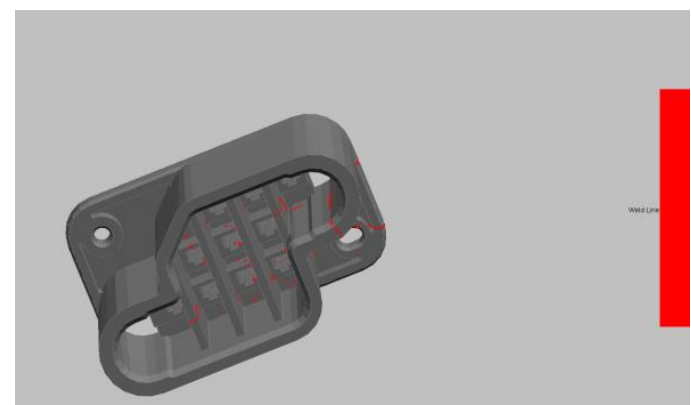

Fig 4.7: Component Weld Line Run 1

In first trial, gate location is given on top surface of the component. As seen in the results, component is not filled completely and present of high number of weld lines in critical areas may lead to failure of same. Therefore gate location is shifted to either sides of component as another simulation run is done.

Trial 2:

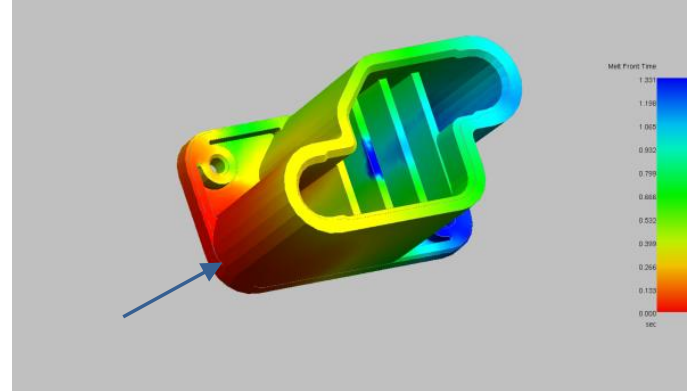

Fig 4.8: Component Fill Time Run 2

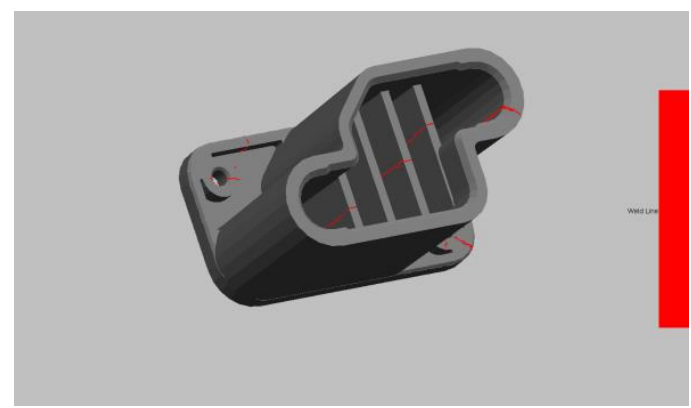

Fig 4.9: Component Weld Line Run 2

In the second trial, gate position is given in the side of component. As seen in the results the complete filling is achieved with reduced number of weld lines. Therefore this position is considered to be the best gate location and implemented in the design.

\section{Tool Design:}

While designing the tool for component, following considerations are taken:

\section{Number of cavities: 4}

Type of Gate: Tunnel/Submarine Gate

Type of Tool: 2-plate

Ejection System: Pin ejection

There are other considerations to be taken such as the design outlook, production order, shrinkage, material usage, etc. The fixed and moving half of the mold is separated at the parting line. After study of component a flat parting is best suited.

The first step after designing the component is the core cavity extraction for a single component and multiplying it into four cavities. The extraction is also done in the NX11.0 software using layers and surface modelling. It is important to extract the main insert and 10 contacts inserts separately. This is due to high production and accuracy, the contact inserts are manufactured separately precision fitted with shoulders in main inserts. These cavity inserts are present on both cavity and core sides. The contact inserts have critical dimensions and if in case they break or wear out, only the particular insert can be changed easily instead of changing the whole insert.

The next step is design of feed system for component. The feed system consists of the sprue, runner, sub-runners and gate. Plastic material first flows from the nozzle to core and cavity through a sprue bush and then fills the runner and gate.

Gate:

The gate is passage through which molten plastic flows 
from runner to cavity of component. The dimensions of gate are usually smaller than the runner to allow the plastic flow at high pressure. This avoids the formation of weld lines, short fills and other defects. There are various types of gates such as sprue, edge, ring, submarine, fan, pinpoint, etc. The type of gate is decided on various factors. The gate should not be located at an area where there is functionality of part. This is because the gate after sheared from component leaves a witness mark. Again the size of witness mark depends on type and dimensions of gate. The customer specifies prior to design if he does not want the gate witness mark on an area. Then the type of gate is decided according to production rate and allowed size of witness mark. Flow analysis and defect analysis is done to decide the best gate position, type and dimensions.

Submarine gate is used in this mould. This is to avoid extra de-gating work and the auto de-gating system can be incorporated in a two plate mold itself. The gate starts from the runner with more diameter then decreases as it comes in contact with component at an angle between 30 to 60 degrees. The witness mark left is also small compared to other gate types.

The gate dimensions can be determined by gate calculations or experience. However the gate opening size is taken from minimum and can be increased later if there any defects.

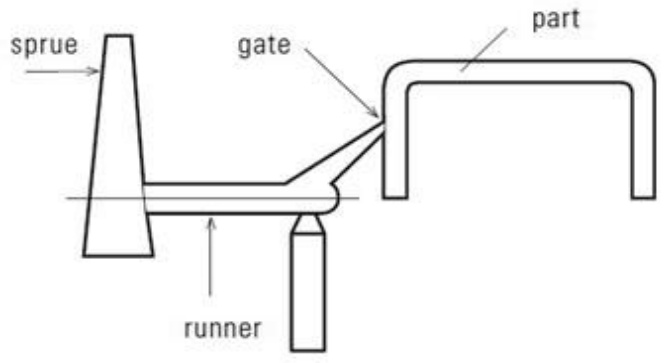

Fig 4.10: Submarine Gate

\section{Core and Cavity:}

In injection moulds usually there are two halves and the fixed half houses the cavity inserts and moving half houses the core inserts. Since the ejection system is in core side, the component should catch to the same side. Core cavity is extracted using NX11.0 software and the ten contact cavities are extracted separately.

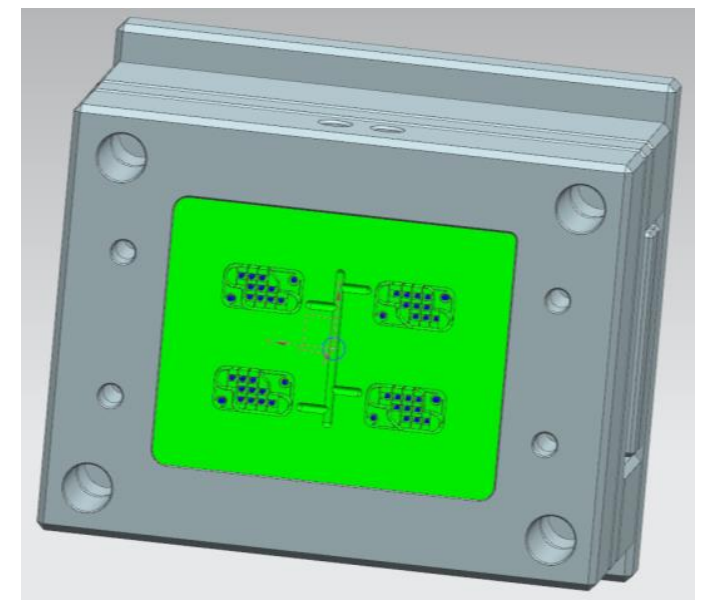

Fig 4.11: Core Half

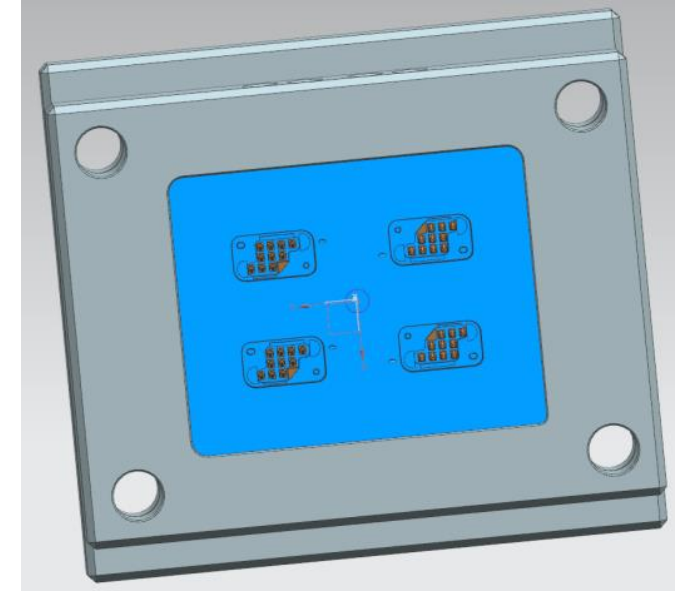

Fig 4.12: Cavity Half

\section{Ejection System:}

A mechanism is always needed to push the component out of the mould. This is called ejection system. There are various ways ejection is possible such as pin ejection, sleeve ejection, plate ejection, air ejection, etc. For this mould the common type is used i.e. pin ejection. This involves pushing the component out by force by circular steel rods knows as ejector pins. The pins are headed and facilitates in the ejector plate supported by ejector back plate. Ejector pins slide in the mould plate by a good sliding fit.

\section{Full Mould Design:}

The full tool assembly is designed. Elements such as locating ring, sprue bush, guide pillar, guide bushes and sprue puller are designed according to the standard shape and size available. The guiding elements are for easy movement as well as accurate guiding. The $\mathrm{Z}$ type sprue pullers are used to hold the shot in core half of the mold during opening. Rest buttons are given in between ejector back plate and bottom plate to give clearance between them so any dust or other particles do not cause any obstruction.

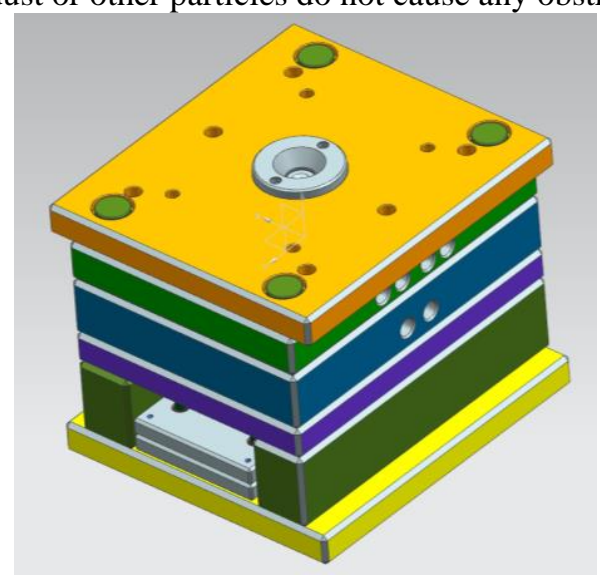

Fig 4.13: Full Tool Assembly

\section{CONCLUSION}

In this paper, tool design and analysis for 10 position drawer housing connector is done in NX 11.0 software. 
The complete injection mould tool is fabricated according to the design and parameters are set according to the given conditions. The various mould elements such as top plate, bottom plate, core cavity inserts, ejector plates, guide pillars and bushes are manufactured. Some standard parts are bought from market. Trial is taken of the mould and the component is checked for defects. If there are any defects because of the mould, minor corrections are done and checked.

\section{REFERENCES}

[1] Design and Analysis of Ceiling Cable Holder Base. Nitish Kumar Mishra1, Prof. Vaibhav Bankar.

[2] Conceptual Design Of Injection Mold Tool For The Chair Hand Rest Component. Sampath.A, Hemanth.R.

[3] Design of Family Mould Tool for Plastic Box. Mohit Milind Sardare, Vaibhav Bankar.

[4] Optimizing the Die Design Parameters for FRP Components Produced in Injection Molding using Mold Flow Analysis. Dr.J. Fazlur Rahman, Mohammed Yunus, Mohammed Irfan, T.M. Tajuddin Yezdani.

[5] Injection Moulding Tool Design Manufacturing, Estimation and Comparison of L\&T Power Box Side Panel Using Plastic Materials HDPE, ABS, PP and PC. N. Sreenivasulu, Dr. D. Ravikanth.

[6] Flow analysis of the weld line formation during injection mold filling of thermoplastics. Tham Nguyen-Chung

[7] Design and Simulation-Based Optimization of Cooling Channels for Plastic Injection Mould. Hong-Seok Park and Xuan-Phuong Dang 